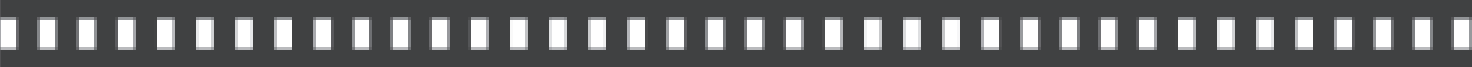

\author{
Entrevista: \\ Tiago Santana
}

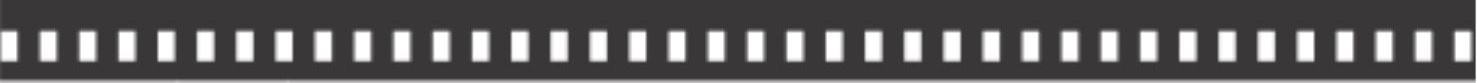

Fernanda Oliveira 


\title{
Fotografia de gente
}

\author{
Fernanda Oliveira*
}

Algo se desnuda nas fotografias de Tiago Santana: um olhar sobre gentes, um olhar humano, uma experiência dividida com o outro, sem receios. Acima da imagem, a vida. Exposta em suas fotografias, sua relação com o sujeito fotografado é a essência do próprio ato. "Para mim, só tem sentido porque minha fotografia é uma fotografia de gente. Eu não sou um fotografo de paisagem, a fotografia que me interessa é a de pessoas", diz.

Entre tantos nomes da fotografia brasileira, destaca-se hoje o nome desse cearense do Cariri, autor dos livros Benditos e Chão de Graciliano, entre outras obras. Importantes acervos nacionais e internacionais reconheceram seu talento e adquiriram fotografias de Tiago Santana.

Indicado duas vezes como melhor fotógrafo documental brasileiro, Tiago se dedica à fotografia desde 1989, sempre com uma forte referência ao Nordeste brasileiro. Em 2010, completa 21 anos de profissão. Para comemorar, apresenta um novo ensaio, intitulado Incompletudes.

Em 2006, venceu o Prêmio Conrado Wessel de Arte, Ciência e Cultura com o ensaio fotográfico Chão de Graciliano. Também fundou a editora Tempo d'Imagem, especializada em livros de fotografia, na qual tem parceria com o fotógrafo Celso Oliveira. É um dos fundadores do Instituto de Fotografia do Ceará (Ifoto), que tem por objetivo estimular a produção fotográfica e seu amadurecimento nas áreas artísticas, cultural, de meio ambiente e de turismo. Além de relevante produção criativa e institucional, Tiago Santana compõe mesas curadoras de importantes festivais, contribui para publicação de livros fotográficos, com circulação nacional, e para o desenvolvimento da pesquisa em fotografia. Por tudo isso, demarca seu espaço na fotografia nacional, da qual é um de seus expoentes.

\footnotetext{
*Jornalista e publicitária. Especialista em Teorias da Comunicação e da Imagem pela Universidade Federal do Ceará (UFC). Mestranda em Comunicação e Linguagens - linha de pesquisa em Fotografia e Audiovisual (UFC). Trabalhou quatro anos como fotojornalista do Jornal Diário do Nordeste. Autora dos livros: Mulheres Líderes no Sertão Central do Ceará e Santa Terezinha: o Morro de uma cidade, pelos quais foi agraciada com cinco prêmios e exposições. É Diretora Executiva do Instituto de Fotografia do Ceará (IFOTO) e leciona na Estácio Ensino Superior de Fortaleza - CE.
} 


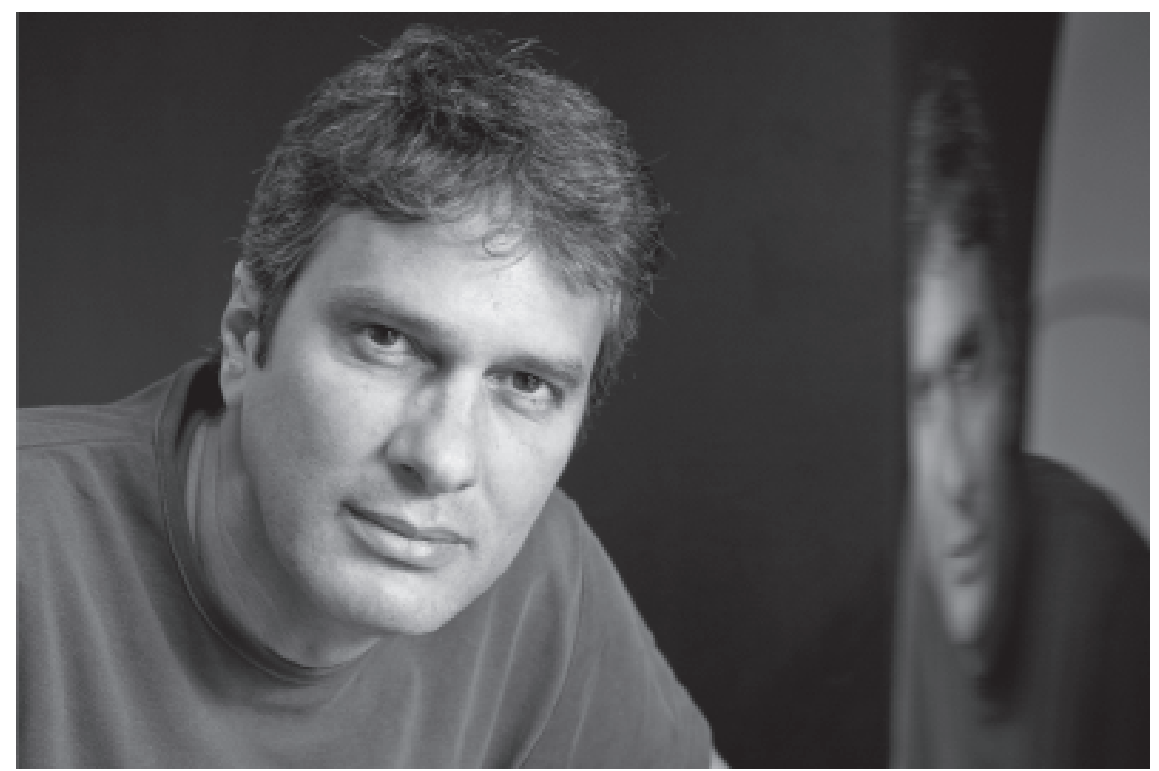

Tiago Santana

Fotografia: José Wagner

\section{Entrevista}

Fernanda Oliveira - O que o motivou a buscar a fotografia, como você acabou entrando nessa área?

Tiago Santana - Olha, são várias coisas que me fizeram entrar na fotografia, mas acho que talvez a mais determinante foi eu ter nascido na região do Cariri, lá em Juazeiro. O lugar, visualmente, é muito rico, muito complexo. Do ponto de vista de uma criança, que começa a descobrir o mundo, um lugar desses é interessante. E, além disso, eu tinha uma relação com imagem influenciada pelo meu pai, Francisco Pereira. Ele tinha câmeras para fotografar, tinha um laboratório improvisado - que revelava preto e branco, no banheiro -, aquelas coisas bem improvisadas, amadoras. E ele fazia muito super oito. $\mathrm{O}$ 
super oito foi a grande escola de cinema. E nessa época eu estava fazendo um monte de super oito e eu comecei pelos super oito. Outro fator que tem a ver com um familiar também, o José Albano. A minha tia é irmã dele e, por meio dela, tivemos uma certa convivência. Ele morava na casa da mãe e tinha um laboratório. Então, teve a ajuda do meu pai, teve a convivência com o José Albano e teve Juazeiro, que é uma síntese do Nordeste todo. Juazeiro foi fundado pelo Padre Cícero, que é cratense, mas na realidade, a cidade foi fundada por pessoas do Nordeste inteiro. Então foi pernambucano, alagoano, baiano e tal. Sempre quando tem muita mistura, muita diversidade, os lugares são muito ricos, né? Essa riqueza de Juazeiro, visualmente, é muito forte. Bom, aí também foi determinante eu ter nascido lá. Agora, eu descobri um pouco da fotografia lá em Juazeiro, mas não me tornei um fotógrafo morando lá. Eu tinha a fotografia como uma coisa importante na minha vida, mas era só um hobby.

Fernanda Oliveira - Então você não pretendia se profissionalizar, era um hobby...

Tiago Santana - Quando vim para Fortaleza fui fazer engenharia mecânica. Eu fui fazer universidade. A universidade foi determinante para a minha percepção de ser fotógrafo, de me tornar um profissional. Nessa época, quando eu estava na universidade, aconteceu a Semana Nacional de Fotografia, organizada pelo INFoto - Instituto Nacional de Fotografia. Eles organizavam semanas nacionais pelo Brasil inteiro. E aí o que aconteceu? Eles estavam ocupando o auditório da reitoria também, com eventos, palestras. E eu caí meio que de paraquedas nessa história, porque eu tinha interesse em fotografia e fui ver. E aí eu descobri, como digo sempre, que a fotografia não era só uma coisa isolada. Existia um movimento, os caras fotografando, pessoas pensando em fotografia, discutindo, eventos, workshops, enfim, tinha algo mais que aquela coisa individual. Existia um grupo de pessoas que só pensava fotografia. Foi aí que deu um estalo. Foi nesse momento que eu mudei, fui abandonando a engenharia e entrando na fotografia. 
Fernanda Oliveira - Você disse que foi desistindo da engenharia e entrando na fotografia. Sabemos que a fotografia publicitária é bastante rentável; no fotojornalismo o profissional ganha o suficiente para sobreviver; o fotógrafo free-lancer faz um pouco de tudo... E no caso do fotógrafo documental, que é a sua área, como é que fica a questão da sobrevivência? Dá para viver da fotografia documental no Brasil?

Tiago Santana - Quando resolvi trabalhar com fotografia, ela era além de um negócio pra mim... era um veículo de comunicação superior... Então tinha esse lado. Óbvio que eu tinha de me sustentar disso, viver disso. Então, eu fiz de tudo na minha carreira, no início. Comecei a trabalhar em todas as áreas, fiz muita coisa de fotojornalismo, trabalhei para Veja, sempre como "freela". Fiz muita coisa para agências de publicidade também. Enfim, isso são coisas que andaram paralelas à minha fotografia, digamos, autoral. Na realidade eu não era pago para isso, né? Mas com livros vendidos eu tive duas bolsas, além de outros prêmios conquistados no exterior. Então, eu fui me dedicando cada vez mais a esses projetos. Aí surgiu a ideia do banco de imagens, com o Celso (Oliveira).

Eu conheci por coincidência o Celso, em uma semana que nós fomos a Ouro Preto. E foi uma identificação muito grande. Nós começamos a trabalhar juntos porque o Celso era dos poucos fotógrafos que tinha a fotografia como algo muito mais importante que um trabalho comercial. E eu me identifiquei muito com isso. Então, assim, ficamos muito ligados, por um trabalho meio coletivo, embora muito individual de certa forma, mas é coletivo também.

Fernanda Oliveira - Essa era uma pergunta que eu ia fazer: o sentido coletivo e individual da fotografia...

Tiago Santana - Eu considero que a característica do ser fotógrafo é uma coisa individual, do ato, mas o resultado tem a ver com a experiência coletiva. Não é que eu não tenha minha autoria, o meu trabalho é meu. É diferente, por exemplo, do Luciel Dakota, que não faz questão de ser um autor individualizado. Mas, hoje em dia, até acho que o meu trabalho, o do Celso e o de muitos outros fotógrafos são fruto de um coletivo de 
fotógrafos que documentam o país. Isso tudo constrói um trabalho, não é uma coisa só minha, entendeu? Eu acho que é um processo.

Fernanda Oliveira - A fotografia é um trabalho individual, mas uma coisa que eu tenho percebido é que, em tese, você só pode construir um livro quando tem a noção de grupo. Na hora de fazer é uma coisa, mas a forma como a fotografia é colocada numa exposição, como é exposta num livro, enfim uma série de olhares e intervenções até a sua finalização pode, inclusive, mudar o olhar dessa fotografia. Você concorda?

Tiago Santana -Lógico. Mas esse processo também é individual, porque você tem escolhas, tem um caminho. A edição é um exemplo muito forte dessa coisa coletiva. É muito complicado fazer sozinho a edição de um livro, que é produto final de um trabalho. Inclusive, acho que a fotografia deixa margem para um outro completar, para outros interagirem. Às vezes, nem sempre a gente ser completo é o melhor; às vezes o incompleto é melhor que o completo.

Fernanda Oliveira - Fale um pouco mais sobre isso...

Tiago Santana - Eu estou fazendo um trabalho para 2010, quando completo 21 anos de carreira. Vou desenvolver um projeto que se chama incompletude. Estamos num processo de aprendizado, o tempo todo, né? Então, incompletude em todos os sentidos: de tempo, de vida, 21 anos... Enfim, de fotografia ou de idade. Acho que é incompleto para você ir buscando. Se você tiver tudo completo, tudo bem resolvido, não funciona... Brincar um pouco com essa coisa de completude. Isso me interessa fragmentadamente, incompleto, porque outro vai completar meu discurso. Então vamos interagir.

Fernanda Oliveira -E sobre o surgimento da Tempo d'Imagem? Começou como um banco de imagens e hoje é uma editora...

Tiago Santana-A ideia era ter uma referência no Nordeste, pois de todas as partes do Brasil nos solicitavam muitas imagens. Até hoje pedem, mas na época não havia tantas opções de fotógrafo e de banco 
de imagens. Decidimos montar uma pequena estrutura. Começamos a trabalhar e fomos convidados a fazer um livro de Fortaleza, o Fortaleza em $7^{\circ}$. Tive oportunidade de fazer um livro histórico sobre a cidade, encomendado pela Prefeitura Municipal de Fortaleza. Foi uma experiência tão legal, que começamos a desbravar esse nicho. Aqui, estou falando de 20 anos atrás. E aí começamos a ver, eu principalmente, a questão das leis de incentivo que eram usadas no cinema. Muitas produções cinematográficas eram todas patrocinadas por leis de incentivo. Por que não os livros, então? Então a gente começou a entrar nessas coisas. Era uma oportunidade de desenvolver nossos projetos e por isso criamos a editora. Agente propõe e corre atrás das leis de incentivo, porque a editora propriamente não tem dinheiro. Ela tem ideias e projetos. Boas ideias e bons projetos. E foi assim que eu encontrei o meu espaço, quero trabalhar com projetos. Acho também que temos que ter o tempo das coisas, observar consistência e maturidade. Também não dá para fazer um ensaiozinho rápido e já querer publicar um livro, né?

Fernanda Oliveira - Recentemente a Tempo d'Imagem lançou a coletânea Encontros com a Fotografia. De onde surgiu essa ideia? Qual é a proposta?

Tiago Santana-Há anos a gente vem pensando num projeto com essas características. Produzir livros teóricos, de texto, que discutam a fotografia. Ninguém vai sair do foco fotografia. Queremos incentivar um pouco esse lado, não só imagens. O Encontros com a Fotografia é fruto desse nosso desejo de fazer outros tipos de livros. Temos uma parceria com a FNAC e essa edição ficará restrita às lojas da FNAC.

Fernanda Oliveira - A Tempo d'Imagem tem algum outro projeto de destaque?

Tiago Santana - Surgiu um projeto fantástico, que será concluído em 2011. É um livro para comemorar o centenário de Juazeiro do Norte e a relação da cidade com a fotografia. Para mim, este é um projeto especial. Vou desenvolvê-lo com muito carinho. Ele passa pela fotografia 
popular, pelos primeiros fotógrafos documentais da cidade. Vamos fazer uma pesquisa sobre isso e também os que já publicaram livros que tenham Juazeiro incluído. OZé Davi tem um livro, o Christian Cravos fez um livro de rebentos, que tem fotografias de Juazeiro. Muita gente já fez livros que tem um pouco de Juazeiro. Então, nossa proposta é enumerá-los, mostrar um pouquinho de cada um deles... Será um ensaio da cultura de Juazeiro.

Fernanda Oliveira-A temática sertão é recorrente no seu trabalho, não é?

Tiago Santana - Os meus dois principais trabalhos em livros são Benditos e o Chão de Graciliano que, de certa forma, têm muito a ver um com o outro. Um nasceu por conta do outro. É... Primeiro porque tem relação com o lugar onde eu nasci. Então, acho que parte desse princípio: meu primeiro trabalho foi vendido por causa da minha relação com aquele lugar. Fazer a minha visão de Juazeiro, a visão de quem não é de fora, mas de uma pessoa "de dentro", que interage com a comunidade, uma visão que não seja a jornalística, tão frequente né? O livro não tem nenhuma fotografia da estátua do Padre Cícero inteira, não essas coisas, essas "obrigações". Talvez seja isso que o difira um pouco do fotojornalismo, pois não tem as obrigações que o fotojornalista de certa forma tem, a obrigação com o leitor, com o veículo de comunicação, né? Eu não tenho obrigação com o outro, tenho obrigação comigo mesmo. Obviamente que tenho respeito e obrigação com quem irá ver o livro, mas não é uma coisa dirigida.

Fernanda Oliveira - O Incompletudes vem ao encontro de seu trabalho desenvolvido até agora sobre o sertão ou irá representar um novo Tiago?

Tiago Santana - Não, outro Tiago não. Todo dia é um Tiago novo, mas o Incompletudes ainda está em processo de maturação. Ele não tem tema nem lugar definidos. Poderá conter fotografias de um país, como fotografias de Juazeiro, entendeu? Poderá ter uma fotografia de São Paulo, mas ainda não está ainda fechado, não. Mas ele é uma coisa simples, até 
porque ainda está incompleto, e vai continuar incompleto. Mas assim, eu tenho outros livros... O livro Brasil sem fronteiras não tem nada a ver com sertão. Ele foi todo feito nas fronteiras do Brasil, pegando aquelas linhas de fronteira, e o mote era que a fronteira demarcada não divide um país de outro, ela une, é um encontro. Eu também já participei de vários outros projetos que não tratavam necessariamente de sertão. Agora, eu tenho uma ligação inevitável com o sertão. Tenho vontade de fazer um livro sobre o semiárido, eu tenho outros desejos.

Fernanda Oliveira - Para você, como a fotografia cearense é vista hoje?

Tiago Santana - Olha, eu a vejo com muito bons olhos. Acho que tem muita coisa nova. Tem uma turminha nova aí que tem construído coisas boas. Acho que é preciso olhar para esse trabalho com calma, com mais cuidado, porque a fotografia ficou algum tempo parada nos mesmos fotógrafos. A gente tem a tendência a ter aqueles ciclos da fotografia. A gente não tem muito esse cuidado de olhar para a nova geração. É por isso que acho que um livro da história da fotografia no Ceará, fazendo um levantamento do que é, descobrir o que foi até os dias de hoje é muito importante. Eu acho que tem muita coisa, muita gente nova produzindo... Claro que isso precisa amadurecer. Porque tem aquele aspecto que eu já falei: muita gente nova que vai fazendo e já quer expor, quer mostrar, quer publicar. Hoje é o tempo da pressa, da ansiedade. Eu sempre digo para quem me pergunta sobre esses fotógrafos iniciantes: "É preciso um pouco de tempo para amadurecer o trabalho." Quando eu conto que esperei oito anos até expor o meu trabalho, as pessoas não acreditam. Mas eu acho que o tempo é uma coisa importante em todos os sentidos, para o trabalho, para a discussão, para um livro. E aí eu acho que o que talvez esteja faltando para a nova geração de fotógrafos é um pouco disso: tentar parar um pouco para poder produzir um trabalho legal.

Fernanda Oliveira - Existe certa dificuldade para a fotografia cearense entrar no cenário nacional. Mas você vem conseguindo isso, 
pois já foi duas vezes indicado como melhor fotógrafo documental. Como você vê esse reconhecimento?

Tiago Santana-Olha, é claro que eu fico feliz com esse resultado fantástico, não pode deixar de ficar, né? Mas eu nunca faço um livro pensando se vou fazer sucesso. Mas, agora, retorno é sempre bom. Eu sou sempre enquadrado na discussão da fotografia documental. Nem sei bem exatamente se é isso mesmo. Eu pelo menos não tenho ainda a noção exata do que seja fotografia documental, sabe? Eu acho que a gente tem que refletir mais sobre o que é a fotografia documental, o porquê de ela ser chamada de documental. Confesso que eu tenho até certo preconceito com esse nome... Não sei porque, mas acho esse nome meio frio, sabe? Mas é onde meu trabalho se encaixa hoje. É porque meu trabalho não é fotojornalismo, né? Ele pode até ser fotojornalismo, mas não o enquadram como fotojornalismo.

Fernanda Oliveira - Como você vê o estreitamento da relação da escola com o mercado de trabalho?

Tiago Santana - Acho que está havendo uma diferença na fotografia. Agora temos pessoas formadas em fotografia. Tem uma nova geração de fotógrafos, hoje em dia, que faz academia, que também acho interessante. Eu sou de uma geração de autodidatas, mas a geração nova sai toda da universidade. Assim, tem muita gente que já reflete mais sobre seu trabalho, tem, assim, uma coisa mais teórica, que eu acho maravilhoso. Penso que um pouco mais à frente veremos um bom resultado disso. Hoje, acho que essa interação é fantástica, não só na fotografia, mas em todas as áreas. Acho isso superinteressante: gente da sociologia, da psicologia, da literatura que junta com a fotografia, enfim.

Fernanda Oliveira - Então esse estreitamento escola e mercado não é ficção?

Tiago Santana - Acho que não. Acho, inclusive, que pode ser também um processo de produção artística, que depende de outro tipo de mercado. 
Fernanda Oliveira - Como você vê a multiplicação de eventos ligados à fotografia?

Tiago Santana - Desde quando comecei a fotografar isso vem acontecendo. Agora, acho que tem que consolidar a maioria dos festivais que são importantes, né? Isso para tentar fortalecer esses movimentos nos festivais, para que eles tenham apoio institucional. Os pequenos festivais, hoje em dia, no mundo todo, por exemplo, têm um grande apoio do ministério da cultura de seus países. Então, acho que a Funarte tem o papel importante de fortalecer essas iniciativas, que é de onde vem, é de onde nasce, é no solo dos festivais que nascem as exposições, que nasce a fotografia. São nos festivais que ela tem espaço para ser vista, sabe? Nesses lugares... São nesses encontros coletivos que nascem as coisas, entendeu?

Fernanda Oliveira - Alguns consideram que a proliferação de eventos pode banalizar a fotografia. O que você acha disso?

Tiago Santana - Não, muito pelo contrário. Esses eventos têm justamente caráter de exposição mesmo, de visibilidade da fotografia, de reflexão sobre imagens, de relatos de experiência de fotógrafos mais experientes, de ver novos trabalhos. Os eventos trazem essa soma de fatores, o que é bom. Acredito que eles estejam sendo muito bons para a fotografia.

Fernanda Oliveira - Que cenários e perspectivas você vê para a fotografia no Brasil?

Tiago Santana - Ah... Sempre muito boas! Eu acho que estamos vivendo um momento politicamente muito bom no Brasil. O país está numa situação privilegiada, economicamente. Temos pela frente uma Copa do Mundo e uma Olimpíada. A gente pensa que não tem reflexos nas outras áreas, mas vai ter reflexo... E tem uma efervescência de produção, de festivais, enfim, eu acho que abre um espaço grande para a fotografia. Já temos grandes fotógrafos, temos uma produção importante, grandes movimentos, tradição, grandes curadores... Então, acho que é um potencial 
que vai ser muito bom nos próximos anos. Está tudo num crescente, e quando eu falo assim, não é crescer por crescer, mas um crescente com gente interessante pensando, com muitas pessoas na academia. Eu acho que essa mistura, que reúne academia, museus, curadores, jornalistas, anais de fotografia, festivais etc., pode trazer excelentes resultados para a fotografia.

Fernanda Oliveira - Hoje estamos descobrindo o valor da fotografia para o resgate e preservação de memória. Mas, descobrimos esse valor com a fotografia analógica, produzida tempos atrás. Será que agora, na era digital, estamos deixando rastros, indícios, documentos confiáveis para que no futuro possam contar a nossa história?

Tiago Santana - Olha, sou uma pessoa que não tem preconceito de nada, inclusive da tecnologia; adoro tecnologia. Mas são coisas que a gente tem que pensar. Quando conto minhas histórias, quero que elas fiquem. Quero que elas fiquem não só nos livros, mas nas fotografias. Eu sei que tem trabalhos de autores contemporâneos em que o efêmero é que é o importante, o que mais importa é aquele momento. Eu até entendo e acho interessante. Mas, acho que uma das coisas interessantes da fotografia é a possibilidade de deixar registros. Pela fotografia, daqui a 50 anos alguém poder refletir sobre o que eu fiz. Contar a história de um lugar, de uma sociedade, de uma cidade, né? Se não fossem os álbuns que foram feitos do Rio de Janeiro, do Marc Ferrez, você não teria noção de como foi a evolução daquele lugar. Então, assim na moda e em outras áreas, a fotografia tem esse papel. Acho que a própria tecnologia está buscando formas de preservar essa produção, acho que existe essa preocupação. Eu, como autor, me preocupo. Faço digital, mas meus trabalhos autorais ainda estão muitos ligados à película. Assim como encanta ao fotógrafo contemporâneo fazer um negócio que se acabe, a mim encanta o processo analógico. Além disso, no processo digital tem muita gente perdendo arquivos. Sei de fotógrafos profissionais que perderam arquivos em HD. Imagina, então, o amador... 
Fernanda Oliveira - Ao longo dessa conversa me pareceu que, para você, o grande barato, na verdade, é a relação com a fotografia...

Tiago Santana - É o que eu acho. O resto é consequência. A minha relação com a fotografia e com os outros, é que é importante. Minha fotografia só tem sentido porque é fotografia de gente. Eu não sou um fotografo de paisagem, a fotografia que me interessa é a de pessoas. $\mathrm{O}$ José Albano diz, e eu acho isso bonito, que a vida é infinitamente maior do que a fotografia. O processo de conhecer a vida em si é muito maior do que a fotografia. E é mesmo, a vida é muito maior, é um processo... Enfim... 